\title{
MicroPPT-Based Secondary/Backup ACS for a 160-m, 450-kg Solar Sail Spacecraft
}

\author{
Bong Wie* \\ Arizona State University, Tempe, AZ 85287 \\ and \\ David Murphy ${ }^{\dagger}$ \\ ATK Space Systems, Goleta, CA 93117
}

\begin{abstract}
Solar sail tip-mounted, lightweight pulsed plasma thrusters (PPTs) are proposed for a secondary (or backup) attitude control system (ACS) of a 160-m, 450-kg solar sail spacecraft of the Solar Polar Imager (SPI) mission. A propellantless primary ACS of the SPI sailcraft employs trim control masses running along mast lanyards for pitch/yaw control together with roll stabilizer bars at the mast tips for quadrant tilt (roll) control. The robustness of such a propellantless primary ACS would be further enhanced by a secondary ACS utilizing tip-mounted, lightweight PPTs. The microPPT-based ACS is intended mainly for attitude recovery maneuvers from various off-nominal conditions that cannot be reliably handled by the propellantless primary ACS. However, it can also be employed for: i) the checkout or standby mode prior to and during sail deployment, ii) the post-deployment transition mode (prior to the propellantless primary ACS mode operation), iii) the solar sailing cruise mode of a "trimmed" sailcraft, and iv) the spin-stabilized, sun-pointing, safe mode. Although a conventional bus ACS is required for the SPI mission as the sail is jettisoned at the start of its science mission phase, the microPPT-based ACS option promises greater redundancy and robustness for the SPI mission. For other sailing missions, where the sail is never jettisoned, this secondary ACS provides a lower-cost, lower-mass propulsion for deployment control and greater redundancy than any traditional reaction-jet control system. This paper presents an overview of the state-of-the-art microPPT technology, the design requirements of microPPTs for solar sail attitude control, and the preliminary ACS design and simulation results.
\end{abstract}

\section{Introduction}

Solar sails are envisioned as a propellantlcss, hight-eĩeigy propuision system for future space exploration missions. NASA's Sun-Earth Connections (SEC) solar sail roadmap missions ${ }^{1-3}$ include the Solar Polar Imager (SPI) mission, L1-Diamond, Particle Acceleration Solar Orbiter (PASO), and Interstellar Probe. In particular, the SPI mission is currently being further explored by NASA/JPL, and it is now called the SPI Vision mission. ${ }^{4}$ Our current understanding of the Sun is limited by a lack of observations of its polar regions. The SPI mission utilizes a large solar sail to place a spacecraft in a 0.48-AU circular orbit with an inclination of $75 \mathrm{deg}$. Viewing of the polar regions of the Sun provides a unique opportunity to more fully investigate the structure and dynamics of its interior, the generation of solar magnetic fields, the origin of the solar cycle, the causes of solar activity, and the structure and dynamics of the corona.

The proposed SPI mission scenario consists of the initial cruise phase (1.6 yr) to a 0.48 -AU circular orbit, the cranking orbit phase ( $5 \mathrm{yr})$, and the science mission phase (2 yr). A 160-m, 450-kg solar sail spacecraft is considered for such a solar sailing mission. ${ }^{4}$ A Delta II launch vehicle is able to inject the $450-\mathrm{kg}$ SPI spacecraft into an earth escaping orbit with $C_{3}=0.25 \mathrm{~km}^{2} / \mathrm{s}^{2}$, and then the sail is to be deployed. The SPI

*Professor, Dept. of Mechanical \& Aerospace Engineering, bong.wie@asu.edu, (480) 965-8674, Fax (480) 965-1384. Associate Fellow AIAA.

${ }^{\dagger}$ Chief Research Engineer, 600 Pine Ave, dave.murphy@atk.com, (805) 690-2439, Fax (805) 685-1369. Member AIAA. 


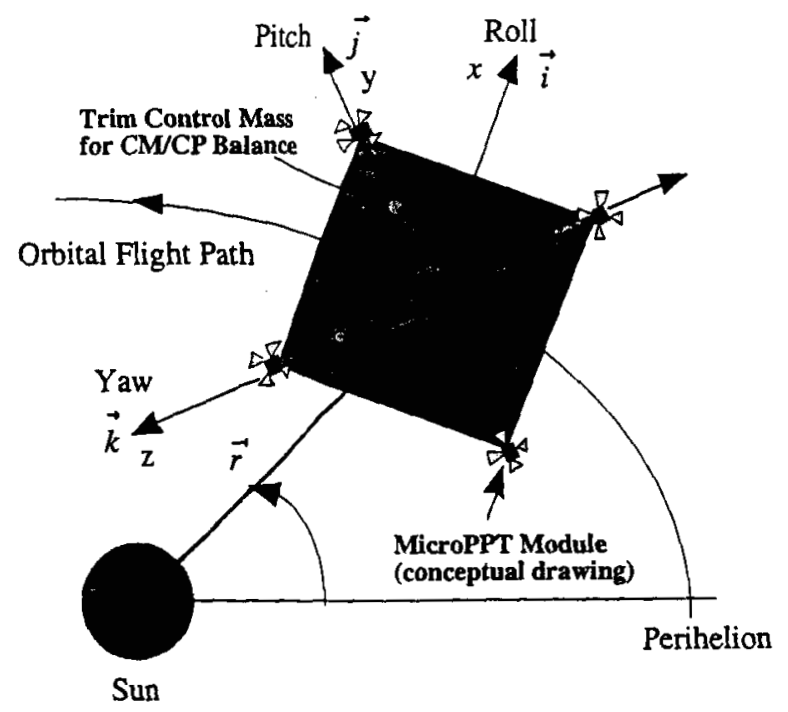

Figure 1. A solar sail spacecraft equipped with a propellantless primary ACS and a microPPT-based secondary (or backup) ACS.

sailcraft first spirals inwards from $1 \mathrm{AU}$ to a heliocentric circular orbit at $0.48 \mathrm{AU}$, then the cranking orbit phase begins with the end result of a 75-deg inclination. The solar sail will be jettisoned after achieving the science mission orbit, and the total sailing time is $6.6 \mathrm{yr}$. A reference SPI sailcraft consists of a 160-m, 150-kg solar sail, a $250-\mathrm{kg}$ spacecraft bus, and $50 \mathrm{~kg}$ science payloads. This $160-\mathrm{m}$ reference sailcraft is characterized by a nominal solar thrust force of $160 \mathrm{mN}$ (at $1 \mathrm{AU}$ ), an uncertain center-of-mass/center-of-pressure offset of $\pm 0.4 \mathrm{~m}$, and a characteristic acceleration of $0.35 \mathrm{~mm} / \mathrm{s}^{2}$.

An attitude control system (ACS), consisting of a propellantless primary ACS and a secondary/backup ACS, is proposed for a 160-m reference sailcraft of the SPI mission, ${ }^{5}$ as illustrated in Fig. 1. The primary ACS employs trim control masses (TCMs) running along mast lanyards for pitch/yaw control together with roll stabilizer bars (RSBs) at the mast tips for quadrant tilt control, as illustrated in Fig. 2. The robustiness of such a propellantiess primary ACS would be further enhanced by a secondary ACS utilizing tip-mounted, lightweight pulsed plasma thrusters (PPTs). Although a conventional bus ACS is required for the SPI mission as the sail is jettisoned at the start of its science mission phase, the microPPT-based ACS option promises greater redundancy and robustness for the SPI mission. A similar ACS architecture was previously studied for a 40-m sailcraft of a near-term solar sail flight validation mission in Refs. 6 and 7 . A potential control-structure interaction caused by the significant torsion and bending of flexible masts of a large sailcraft is discussed in Ref. 8.

In this paper, the secondary (or backup) ACS employing tip-mounted microPPTs is presented. Such a microPPT-based ACS provides reliable capability for recovery of attitude given any off-nominal conditions, including tumbling, that cannot be reliably handled by either the propellantless primary ACS or by the conventional spacecraft ACS. A microPPT-based ACS is also useful for 3-axis stabilization of the sailcraft after release from the launch vehicle, and (most critically) during deployment, and also during pre-flight sail checkout operations as well. Alternately, these "secondary" functions can in general be performed by the conventional spacecraft ACS; however, such systems would be significantly more massive. But the control offered by standard size conventional ACS during sail deployment would not be robust to variations in symmetry during deployment. MicroPPT technology enables a tremendous gain in sailcraft performance, most critically in the areas of agility, mass, and redundancy. Such a microPPT-based ACS significantly increases the overall system reliability and robustness. Experimental study results for developing a 2-kg microPPT module (with an impulse bit of $150 \mu \mathrm{N}-\mathrm{s}$ ) for solar sail attitude control can be found in Refs. 9 and 10.

The remainder of this paper presents a brief description of an integrated attitude and orbit control system (AOCS) architecture proposed for the SPI sailcraft, an overview of the state-of-the-art microPPT 


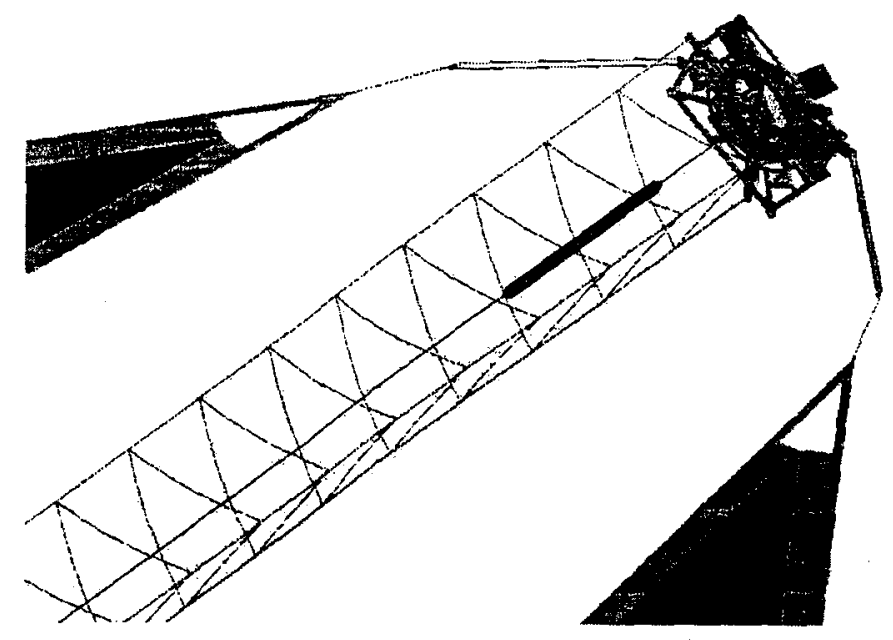

Figure 2. A solar sail mast with a control trim mass (running along a lanyard tape), tip-mounted roll stabilizer bars attached to sail panels, and a tip-mounted microPPT module.

technology, the design requirements of microPPTs for solar sail attitude control, and the preliminary design and simulation results of a microPPT-based ACS.

\section{An Integrated AOCS Architecture of the SPI Sailcraft}

An AOCS architecture, proposed for the robust, reliable thrust vector control of the SPI sailcraft, is illustrated in Fig. 3. The attitude determination subsystem (ADS) is a critical subsystem of most spacecraft AOCS. An ADS of particular interest for solar sail applications is the Inertial Stellar Compass (ISC) recently developed by Draper Laboratory for a New Millennium Program (NMP) ST6 flight validation experiment. The ISC is a miniature, low-power ADS developed for use with low-cost microsatellites. It is suitable for a wide range of future solar sail missions because of its low-mass, low-power, and low-volume design and its self-initializing, autonomous operational capability. The ISC is composed of a wide field-of-view activepixel star camera and microgyros, with associated data processing and power electronics. ${ }^{11}$ It has a total mass of $2.5 \mathrm{~kg}$, a power requirement of $3.5 \mathrm{~W}$, and an accuracy of $0.1 \mathrm{deg}(1 \sigma)$. It is planned to be fight validated within few years. Some recent advances in microsatellite technologies, including the ISC, need to be exploited to complete an integrated low-cost, low-risk, low-mass, low-power, and low-volume AOCS for sailcraft. Detailed analysis and design of this baseline AOCS architecture, as applied to a fight validation mission of a 40-m solar sail in a dawn-dusk sunsynchronous orbit, can be found in Refs. 7 and 8 .

The proposed AOCS architecture, consisting of a propietlantitless primary ACS and a microP'P'l-based secondary ACS, will be applicable with minimal modifications to a wide range of future solar sail flight missions with varying requirements and mission complexity, including a solar sailing mission requiring 160 $\mathrm{m}$ sailcraft for intercepting, impacting, and deflecting near-Earth asteroids. ${ }^{12}$ Although a conventional bus ACS is required for the SPI mission as the sail is jettisoned at the start of its science mission phase, the microPPT-based ACS option promises greater redundancy and robustness for the SPI mission. For other sailing missions, where the sail is never jettisoned, this secondary ACS provides a lower-cost, lower-mass propulsion for deployment control and greater redundancy than any traditional reaction-jet control system. Other solar sail ACS options employing a control boom or control vanes can be found in Ref. 13.

\section{Recent Advances in MicroPPT Technology}

The purposes of this section are to provide a brief overview of the recent advances in microPPT technology applicable to solar sail attitude control and to establish the foundation for developing the microPPT design requirements for solar sails.

A variety of microthrusters for stationkeeping and attitude control of microsatellites are currently under 


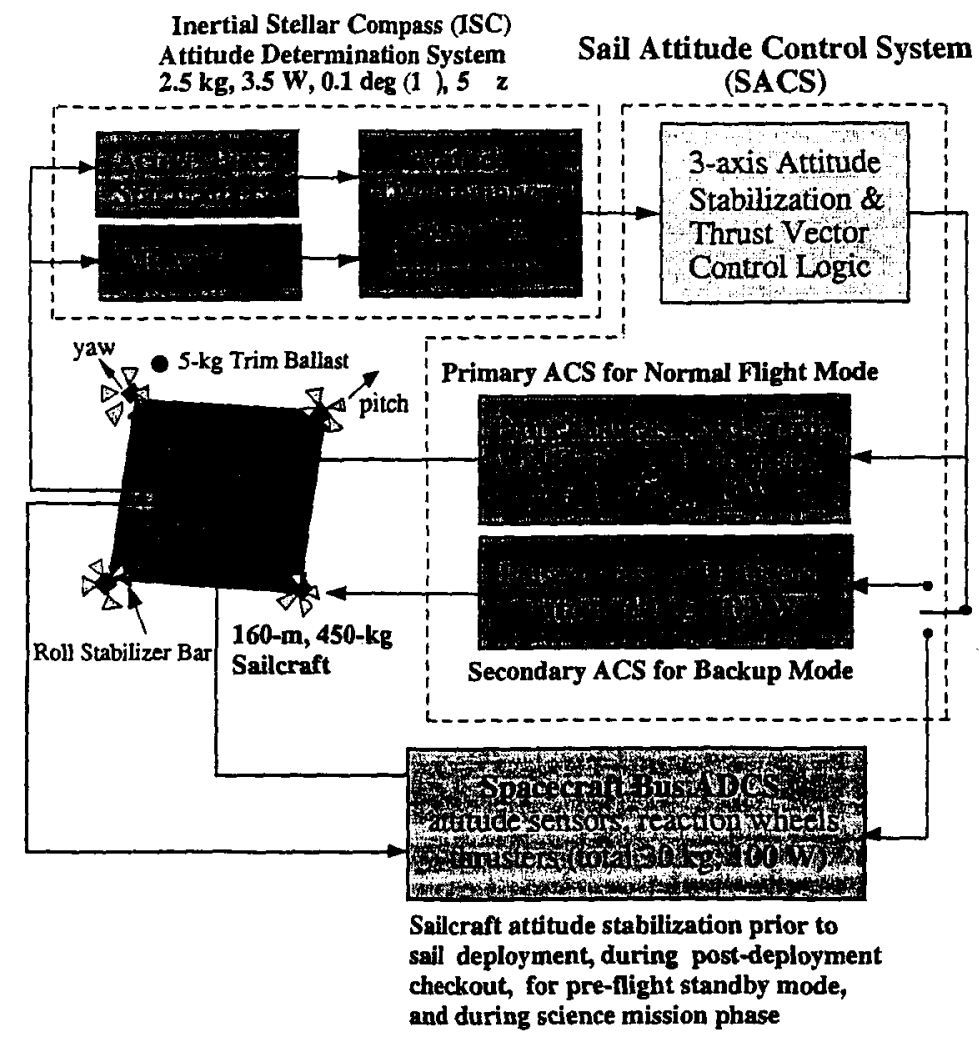

Figure 3. An integrated attitude and orbit control system (AOCS) architecture proposed for the 160-m, 450-kg SPI sailcraft.

significant rapid development by NASA Glenn Research Center, Air Force Research Laboratory (AFRL), Jet Propulsion Laboratory, and industry. ${ }^{14}$ They include: the vaporizing liquid microthruster, the micron-sized cold-gas thruster, the micro Hall thruster, the micro ion engine, the microPPTs, the free molecule microresistojet, and the digital microthruster array. Most of these microthrusters have an inherent problem of low specific impulse and low efficiency. However, such a low-Isp and/or low-efficiency drawback of microthrusters may not be of significant importance for solar sail attitude control applications, whereas other factors such as low thrust, low power, low mass, low volume, low voltage, and low impulse bit are more important. Among these microthrusters, a microPPT is judged most suitable for solar sail attitude control applications because of its inherent simplicity (not requiring propellant tanks, micromachined valves, and complex feed systemis) and its use of a soliu Ten̂on propeilant. ${ }^{i 4-i \hat{o}}$ However, the selection of a particular type of attitude-control propulsion system for a given mission is in general a complex problem, and it is strongly mission dependent.

The PPT, perhaps the simplest electromagnetic propulsion device, uses electric power to ionize and electromagnetically accelerate a plasma to high exhaust velocities. As illustrated schematically in Fig. 4, the PPT consists of a Teflon fuel bar, a negator spring, a power processing unit (PPU), capacitors, electrodes, a spark plug, and a trigger circuit. The main discharge, ignited by the spark plug, ablates and ionizes a small amount of Tefion from the face of the fuel bar into a plasma slug. The plasma is then accelerated to high exhaust velocities by the Lorentz force. The interaction of the current and the self-imposed magnetic field generates the $\vec{j} \times \vec{B}$ Lorentz force.

The PPT technology has a long history of reliable space flight operation; for example, Russian Zond2 Mars Probe in 1964, LES-6 spacecraft (by MIT Lincoln Laboratory) in 1968, LES-8/9 satellites, and NOVA satellites in early 1980 s. $^{14}$ Recently, several miniaturized PPTs have been developed for a variety of satellite applications. For example, the EO-1 PPT by Primex Aerospace (now Aerojet-Redmond) was flight validated on the EO-1 New Millennium Program mission. ${ }^{15}$ A precision pitch attitude pointing capability of a PPT-based ACS was demonstrated for the EO-1 spacecraft while meeting stringent electromagnetic and contamination constraints. A $112-\mu \mathrm{N}$ PPT module was also recently developed for the 15-kg Dawgstar 


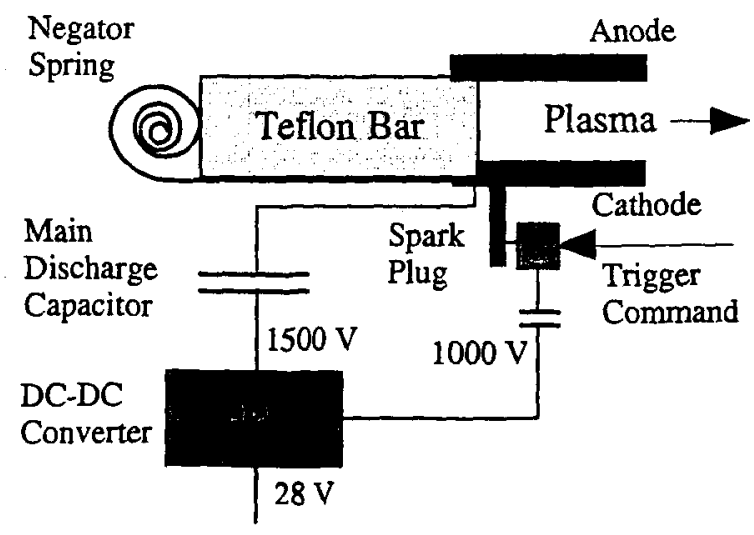

Figure 4. Schematic of a pulsed plasma thruster (PPT).

microsatellite. ${ }^{16,17}$ Although the Dawgstar satellite did not become part of an actual flight program, a flight-qualified unit has been developed for use in microsatellites. ${ }^{17} \mathrm{~A}$ much smaller $10-\mu \mathrm{N}$ PPT unit was developed by the AFRL. ${ }^{18}$ The $10-\mu \mathrm{N}$ microPPTs by the AFRL were originally planned to fly on the TechSat21 mission as a technology demonstration, but they were never flown due to program cancellation of the TechSat21 mission. Such a significant miniaturization was made possible by using a self-igniting discharge, thus eliminating the separate igniter circuit from a standard PPT. ${ }^{18}$

Busek Corporation has taken over commercial development of the microPPT design from the AFRL and is providing microPPTs for the FalconSat3 program at the U.S. Air Force Academy. FalconSat3 is a 50-kg, 0.46-m cube microsatellite scheduled for launch in 2006 using the EELV/ESPA. Among its other mission objectives, FalconSat3 will demonstrate a micro-propulsion attitude control system (MPACS) technology. A microPPT module is also installed at the end of a gravity-gradient boom. Each module of a total mass of $1.6 \mathrm{~kg}$ includes three thrusters, a shared main capacitor, and individual triggering units for each thruster with an impulse bit of $100 \mu \mathrm{N}$-s.

The overall characteristics of these recently developed microPPTs are compared in Table 1.

Table 1. Comparison of recently developed microPPT modules

\begin{tabular}{lcccc}
\hline \multicolumn{1}{c}{ Parameter } & EO-1 & Dawgstar & AFRL- $\mu$ PPT & FalconSat3 \\
\hline Thrust, ${ }^{a} \mu \mathrm{N}$ & $90-860$ & 120 & 10 & 100 \\
Thrusters per module & 2 & 2 & 1 & 3 \\
Pulsing freq. (max), Hz & 1 & 2 & 1 & 2 \\
Impulse bit, $\mu \mathrm{N}-\mathrm{s}$ & $90-860$ & 60 & 10 & 50 \\
Pulse energy, J & $8.5-56$ & 5 & 6.6 & 2 \\
Total module mass, kg & 4.9 & 1 & 0.1 & 1.6 \\
Power, $\mathrm{W}$ & 70 & 15 & 1 & 8 \\
Isp, sec & $650-1350$ & 242 & - & - \\
Efficiency, ${ }^{b} \%$ & 9.8 & 1.8 & - & - \\
Total impulse, ${ }^{c} \mathrm{~N}$-s & 925 & 140 & - & - \\
Propellant, ${ }^{c} \mathrm{~kg}$ & 0.07 & 0.03 & - & - \\
\hline \hline
\end{tabular}

aaximum steady thrust at maximum pulsing frequency.

${ }^{b}$ Thruster efficiency, not including the PPU efficiency.

${ }^{c}$ Per thruster. 


\section{PPT Sizing Requirements for Solar Sails}

The microPPT-based ACS is intended mainly for attitude recovery maneuvers from various off-nominal conditions that cannot be reliably handled by the propellantless primary ACS. However, it can also be employed for: i) the checkout or standby mode prior to and during sail deployment, ii) the post-deployment transition mode (prior to the propellantless primary ACS mode operation), iii) the solar sailing cruise mode of a trimmed sailcraft, and iv) the spin-stabilized, sun-pointing mode.

Table 2 summarizes various physical parameters of the three different sizes of solar sails currently under development by ATK Space Systems. A 40-m solar sail is being considered for a near-term solar sail flight validation mission, and a $80-\mathrm{m}$ solar sail will be required for the Geostorm mission. ${ }^{1-3}$ The SPI mission requires a 160-m solar sail. ${ }^{4}$ The center-of-mass/center-of-pressure offset listed in Table 2 was based on a $0.25 \%$ of each sail size. Such unintentional $\mathrm{cm} / \mathrm{cp}$ offset is caused by the "nominally worst" asymmetry of solar sails. An abnormal asymmetry caused by a sail deployment failure is not treated as the "nominally worst" asymmetry of solar sails for sizing the microPPT-based ACS.

As can be seen in Table 2, the impulse bit size of each microPPT module was selected to provide a control torque with sufficient margins for counteracting the "nominally worst" solar disturbance torque. The maximum pulsing frequency of each PPT module was assumed as $1 \mathrm{~Hz}$ for various practical reasons, although the impulse bit can be reduced if the maximum pulsing frequency increases.

A 2-kg, PPT-150 module with an impulse bit of $150 \mu \mathrm{N}$-s is suggested for a 40-m untrimmed sailcraft with sufficient control torque margins. A pair of thrusters can also be employed to further increase control torque margins, if necessary. It can be noticed that the EO-1 PPT module with a total mass of $4.9 \mathrm{~kg}$ is too heavy and that the thrust level of AFRL's $\mu$ PPT is too low to be employed for a 40-m solar sail. The Dawgstar PPT module with a total mass less than $1 \mathrm{~kg}$ has a thrust level of $112 \mu \mathrm{N}$, but its current design has a total impulse of only $140 \mathrm{~N}-\mathrm{s}$ (per thruster), which is too small for solar sail attitude control applications. Consequently, a prototype lightweight PPT module, named PPT-150, 9,10 is currently being developed for use in solar sail attitude control by employing the design methodology of the flight-proven E0-1 PPT module. As shown in Fig. 6, the PPT-150 module has four thruster units in a cross configuration to be mounted at the tip of a solar sail boom. A mast tip-mounted PPT-150 of a maximum steady thrust level of $150 \mu \mathrm{N}$ (@ $1 \mathrm{~Hz}$ pulsing frequency) provides a maximum control torque of $4.2 \mathrm{mN}-\mathrm{m}$ for a $40-\mathrm{m}$ sailcraft (using a single thruster). A set of four PPT-150 modules, each module with four PPT units of four selectable thrust directions can provide full three-axis control with redundancy. The three PPT units of each module share the main discharge capacitor and the main PPU. The preliminary design characteristics of the PPT-150 module are summarized in Table 3.

A baseline PPT-150 moduie is being developed to be scalable for larger solar sails, as can be seen in Table 2. Because of the extremely large solar disturbance torque acting on a 160-m SPI solar sail, especially at 0.5 AU from the sun, a PPT-1200 module with 12 thruster units, shown in Fig. 5(c), is considered for the 160-m SPI sailcraft. A set of four PPT-1200 modules, each module with 12 thrusters can provide three-axis control torques with sufficient torque margins and redundancy.

\section{MicruPPT-Based ÁCS Design and Simulation}

Similar to mounting control vanes at the mast tips, four PPT modules are mounted at the mast tips, as illustrated in Figs. 1 and 2, to utilize the largest moment arm length. A pitch-axis dynamic model with tip-mounted microPPTs and a trim control mass are also illustrated in Fig. 7.

A single-axis control loop of a typical reaction-jet control system applicable to the microPPT-based ACS is shown in Fig. 8. The pulse width modulator (PWM) shown in Fig. 8 differs from other modulators, such as a pulse width and pulse frequency (PWPF) modulator, that it is essentially a discrete-time device. The output of a PWM is not a thruster firing state; instead, the PWM output is thruster pulse width, as illustrated in Fig. 8. Pulse modulation represents the common control logic behind most reaction-jet control systems of spacecraft. Unlike other actuators, such as reaction wheels, thruster output consists of two values: on or off. Proportional thrusters, whose fuel valves open a distance proportional to the commanded thrust level, are not often employed in practice. Mechanical considerations prohibit proportional valve operation largely because of dirt particles which prevent complete closure for small valve openings; fuel leakage through the valves consequently produces opposing thruster firings. In general, pulse modulators produce a pulse command sequence to the thruster valves by adjusting the pulse width and/or pulse frequency. ${ }^{19,20}$ 
Table 2. Solar sail parameters and PPT module characteristics

\begin{tabular}{|c|c|c|c|c|}
\hline Sail Size & 40 & 80 & 160 & $\mathrm{~m}$ \\
\hline \multicolumn{5}{|l|}{ Geometry } \\
\hline Mast length & 28 & 56 & 113 & $\mathrm{~m}$ \\
\hline Mast diameter & 0.4 & 0.4 & 0.6 & $\mathrm{~m}$ \\
\hline Bending EI & 82,441 & 82,441 & 438,847 & $N-m^{2}$ \\
\hline Torsional GJ & 197 & 197 & 453 & $\mathrm{~N}-\mathrm{m}^{2}$ \\
\hline Scallop factor & 75 & 75 & 75 & $\%$ \\
\hline Sail area & 1,200 & 4,800 & 19,200 & $\mathrm{~m}^{2}$ \\
\hline Solar thrust & 10 & 40 & 160 & $\mathrm{mN}$ \\
\hline $\mathrm{cm} / \mathrm{cp}$ offset & 0.1 & 0.2 & 0.4 & $\mathrm{~m}$ \\
\hline \multicolumn{5}{|l|}{ Mass } \\
\hline Sails & 6 & 19 & 77 & $\mathrm{~kg}$ \\
\hline Masts & 7 & 14 & 68 & $\mathrm{~kg}$ \\
\hline Tip mass (total) & 1 & 2 & 3 & $\mathrm{~kg}$ \\
\hline Central assembly & 8 & 10 & 15 & $\mathrm{~kg}$ \\
\hline Sail propulsion subsystem & 22 & 45 & 163 & $\mathrm{~kg}$ \\
\hline Sail primary ACS & 4 & 6 & 10 & $\mathrm{~kg}$ \\
\hline Sail secondary ACS & 8 & 12 & 20 & $\mathrm{~kg}$ \\
\hline Bus & 150 & 200 & 200 & $\mathrm{~kg}$ \\
\hline Payload & 16 & 37 & 57 & $\mathrm{~kg}$ \\
\hline Total (sailcraft) & 200 & 300 & 450 & $\mathrm{~kg}$ \\
\hline Acceleration (at $1 \mathrm{AU}$ ) & 0.05 & 0.13 & 0.35 & $\mathrm{~mm} / \mathrm{s}^{2}$ \\
\hline \multicolumn{5}{|l|}{ Inertia } \\
\hline $\mathrm{I}_{x}($ roll $)$ & 4,340 & 10,262 & 642,870 & $\mathrm{~kg}-\mathrm{m}^{2}$ \\
\hline$I_{y}$ (pitch) & 2,171 & 20,136 & 321,490 & $\mathrm{~kg}-\mathrm{m}^{2}$ \\
\hline$I_{z}($ yaw $)$ & 2,171 & 20,136 & 321,490 & $\mathrm{~kg}-\mathrm{m}^{2}$ \\
\hline \multicolumn{5}{|l|}{ Solar disturbance torque } \\
\hline Roll (at $1 \mathrm{AU})^{a}$ & 0.5 & 4 & 32 & $\mathrm{mN}-\mathrm{m}$ \\
\hline Pitch/yaw (at $1 \mathrm{AU}$ ) & 1 & 8 & 64 & $\mathrm{mN}-\mathrm{m}$ \\
\hline Pitch/yaw (at 0.5 AU) & & & 256 & $\mathrm{mN}-\mathrm{m}$ \\
\hline \multicolumn{5}{|l|}{ MicroPPT-based ACS } \\
\hline PPT module name & PPT-150 & PPT-300 & PPT-1200 & \\
\hline Impulse bit & 150 & 300 & 1200 & $\mu \mathrm{N}-\mathrm{s}$ \\
\hline Control thrust & $150^{b}$ & $300^{c}$ & $3600^{d}$ & $\mu \mathrm{N}$ \\
\hline Control torque & 4.2 & 16.8 & 407 & $\mathrm{mN}-\mathrm{m}$ \\
\hline Thrusters per module & 4 & 8 & 12 & \\
\hline Module mass (desired) & 2 & 3 & 5 & $\mathrm{~kg}$ \\
\hline
\end{tabular}

$a_{50 \%}$ of pitch/yaw disturbance

${ }^{b}$ using a single thruster with an impulse bit of $150 \mu \mathrm{N}-\mathrm{s}$ (@1 Hz)

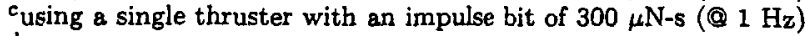

dusing 3 thrusters with an impulse bit of $1200 \mu \mathrm{N}-\mathrm{s}(@ 1 \mathrm{~Hz})$ 

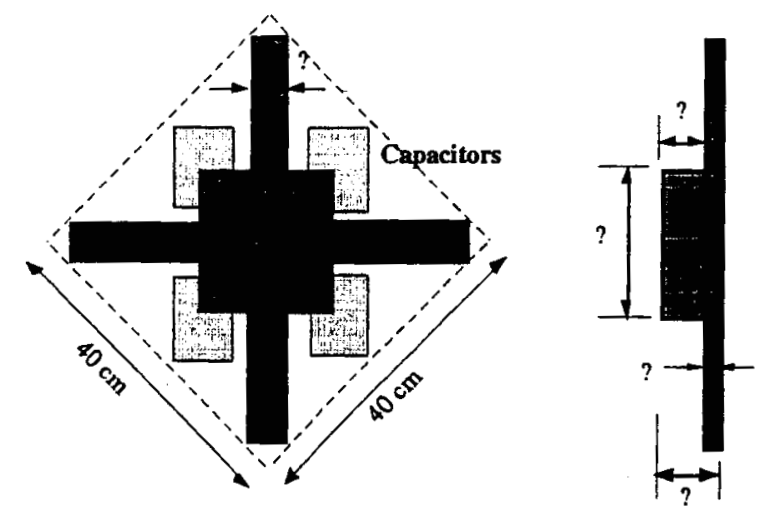

(a) A 2-kg Module with 4 Thrusters
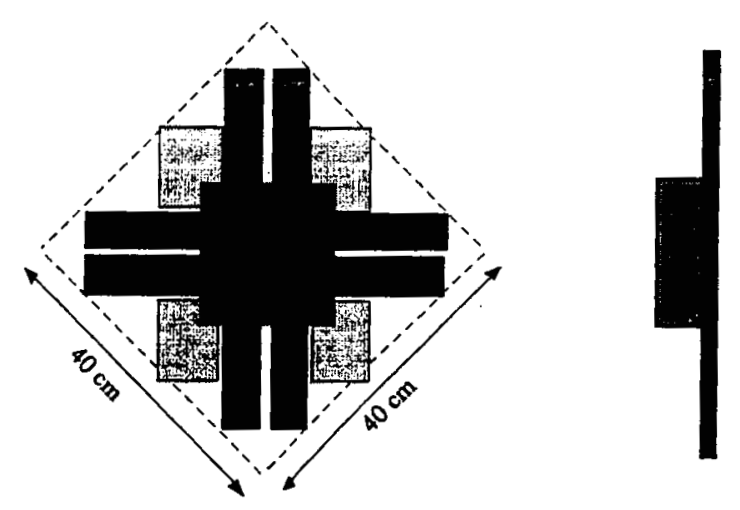

(b) A 3-kg Module with 8 Thrusters
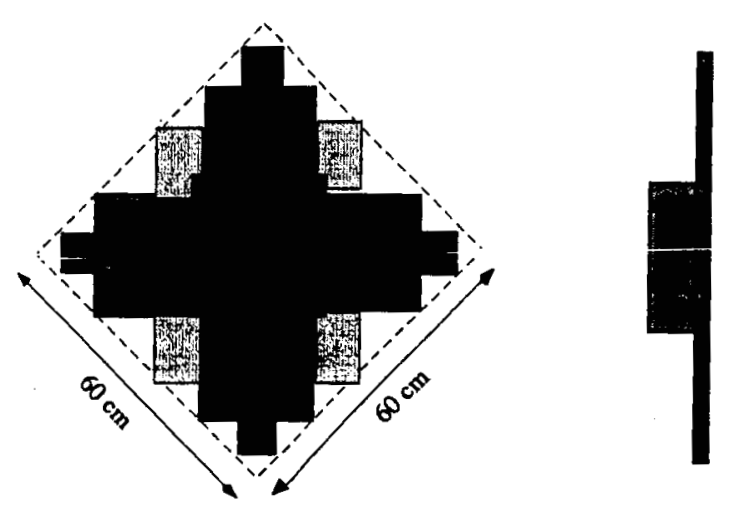

(c) A 5-kg Module with 12 Thrusters

Figure 5. Solar sail $\mu$ PPT module configurations: (a) a $2-\mathrm{kg}$ module with 4 thrusters, (b) a 3-kg module with 8 thrusters, and (c) a 5 -kg module with 12 thrusters. 


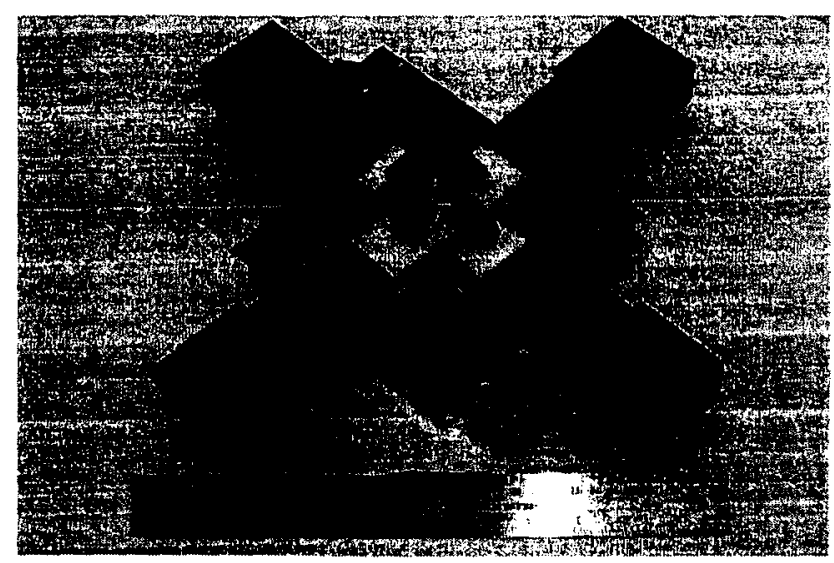

Figure 6. An experimental, low-cost, lightweight PPT-150 module in a cross configuration currently under development (pre-assembled for an illustration purpose).$^{9,10}$

Table 3. Characteristics of the PPT-150 module of a 40-m solar sail.

\begin{tabular}{|c|c|}
\hline Parameter & Value \\
\hline Module mass & $2 \mathrm{~kg}$ \\
\hline Thrusters & 4 \\
\hline Impulse bit & $150 \mu \mathrm{N}-\mathrm{s}$ \\
\hline Pulse frequency (max) & $\mathrm{i} \mathrm{Hz}$ \\
\hline Average thrust (max) ${ }^{a}$ & $150 \mu \mathrm{N}$ \\
\hline Pulse energy & $13 \mathrm{~J}$ \\
\hline Power ${ }^{a}$ & $16 \mathrm{~W}$ \\
\hline Specific impulse & $>500 \mathrm{sec}$ (desired) \\
\hline Efficiency & $>5 \%$ (desired) \\
\hline Total impulse ${ }^{a}$ & $1500 \mathrm{~N}-\mathrm{s}$ \\
\hline Total firings ${ }^{a}$ & 10 millions \\
\hline Teflon mass ${ }^{a}$ & $0.2 \mathrm{~kg}$ \\
\hline
\end{tabular}

aper a single thruster unit. 


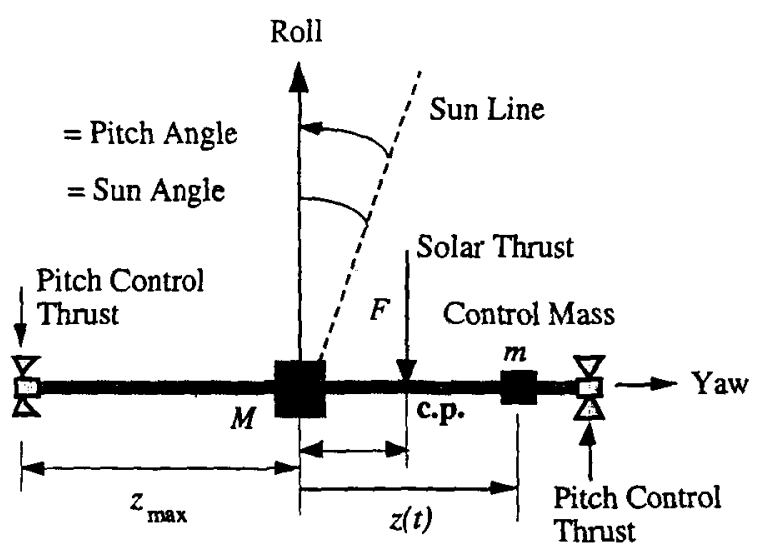

Figure 7. Pitch-axis dynamic model with tip-mounted microPPTs and a trim control mass.

Fig. 8 , the value $d_{1}$ represents the minimum pulse width of the system; this deadzone is directly proportional to the attitude deadband. The value $d_{2}$ represents the maximum pulse width of the RCS; it is often chosen to be the digital control sampling period. The delay in the feedback loop introduces damping to the system; maximum damping occurs when the feedback signal is smaller than the PWM input. If the input signal is not greater than the feedback signal, the modulator may limit cycle itself. This criterion enables the designer to determine the feedback gain, $K_{2}$. The feedforward gain, $K_{1}$, is selected as result of the minimum pulse width and the attitude deadband. More details of pulse modulation techniques as applied to spacecraft attitude control systems design can be found in Refs. 19 and 20 .

As illustrated in Fig. 8, the pulse control logic of employing a variable limiter is given by ${ }^{20}$

$$
u=-\left\{\operatorname{sat}_{L}(e)+K_{r} \dot{\theta}\right\}
$$

where

$$
\begin{gathered}
e=\theta-\theta_{c} \\
L=K_{r} \min \left\{\sqrt{2 a|e|}, \omega_{\max }\right\}
\end{gathered}
$$

and $\theta$ is the pitch attitude angle, $\theta_{c}$ is the commanded pitch angle, $\omega_{\max }$ is the desired maximum slew rate, $a$ is the maximum control angular acceleration.

For a PPT with a fixed impulse bit $\left(I_{b i t}\right)$ and a maximum pulsing frequency of $1 \mathrm{~Hz}$, as illustrated in Fig. 9, we choose $K_{1}=1, K_{2}=0$, and $d_{1}=d_{2}$. A single pulse firing is commanded if $|u|>d_{1}$ where $d_{1}$ is the desired attitude deadband. Preliminary design values of the PPT-based ACS are provided in Table 4.

The robustness of a propellantless primary ACS described in Refs. 5-8 can be further enhanced by the micionFT-vased ACS. A three-axis attitude recovery capability of the microPPT-based ACS is illustrated in Fig. 10 in the presence of a cm/cp offset of $0.4 \mathrm{~m}$ at $0.48 \mathrm{AU}$. After achieving steady-state, near-zero attitude errors at $t=1.5 \mathrm{hrs}$, a propellantless primary ACS (with a trim control mass moving at a maximum speed of $5 \mathrm{~cm} / \mathrm{s}$ ) is activated to trim the sailcraft with $0.25 \%$ residual disturbances, resulting in less frequent thruster firings.

\section{Conclusion}

A secondary (or backup) attitude control system (ACS) of utilizing tip-mounted, lightweight PPTs was presented in this paper. Such a microPPT-based ACS provides reliable capability for recovery of attitude given off-nominal conditions, including tumbling, that cannot be handled by either the propellantless primary ACS or by conventional ACS within the sail carrier spacecraft. MicroPPT-based ACS is also useful for 3-axis stabilization of the sailcraft after release from the launch vehicle, and (most critically) during deployment, and also during pre-flight sail checkout operations as well. 


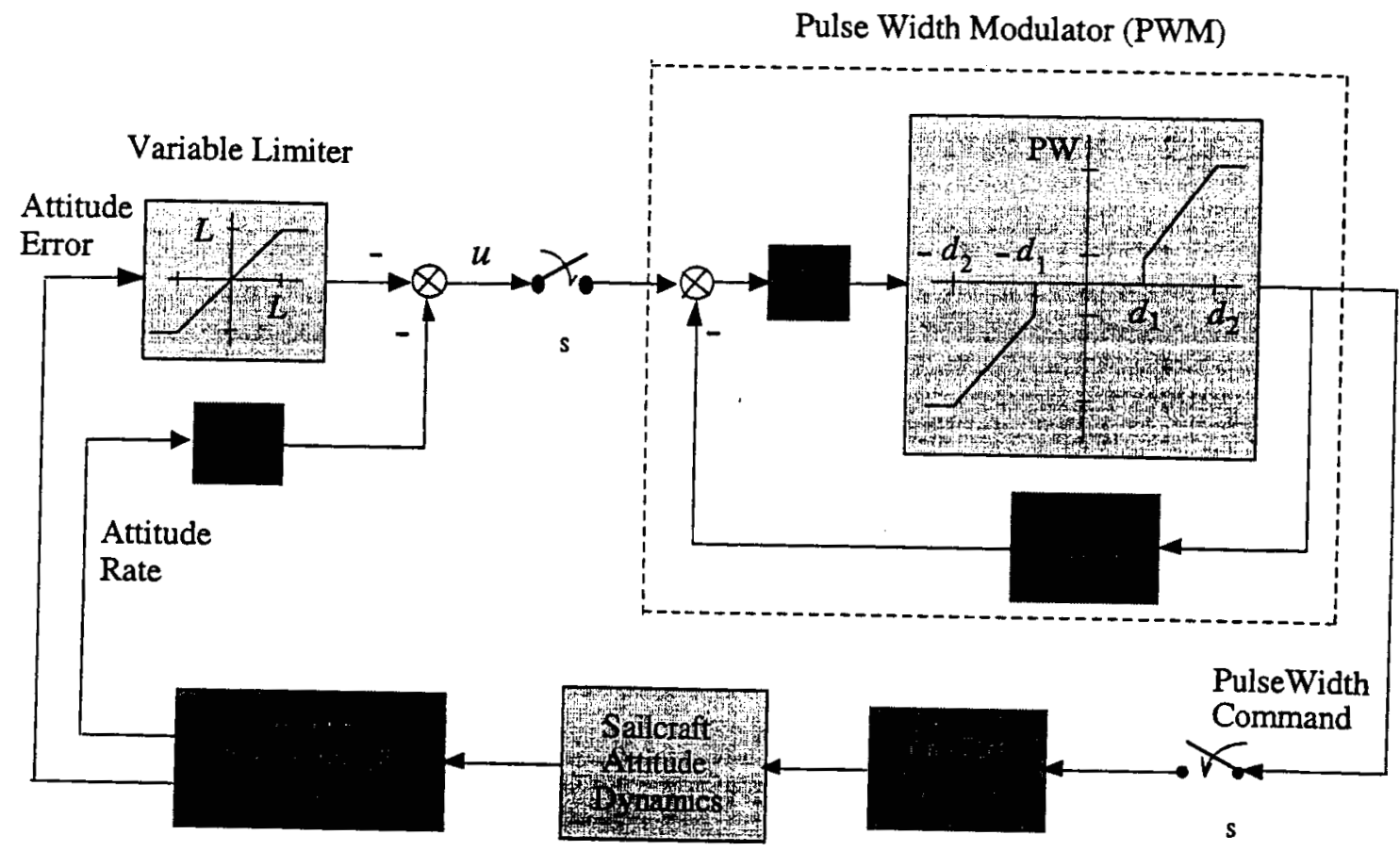

Figure 8. Single-axis control loop model of a microPPT-based ACS.

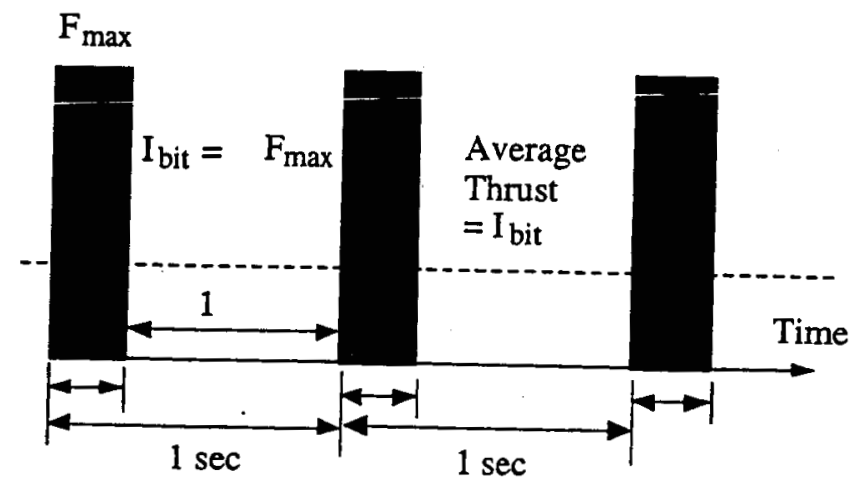

Figure 9. Steady-state pulse firings of a PPT at 1-Hz pulse frequency. 
Table 4. PPT-1200 parameters and control simulation model for the $160-\mathrm{m}, 450-\mathrm{kg}$ SPI sailcraft at 0.5 AU

\begin{tabular}{lc}
\hline Parameter & Value \\
\hline PPT-1200 module mass (with 12 thrusters) & $5 \mathrm{~kg}$ \\
Total PPT system mass (4 modules) & $20 \mathrm{~kg}$ \\
Impulse bit & $1200 \mu \mathrm{N}-\mathrm{s}$ \\
Pulsing frequency (max) & $1 \mathrm{~Hz}$ \\
Pulse energy & $70 \mathrm{~J}$ \\
Power $^{a}$ & $100 \mathrm{~W}$ \\
Specific impulse & $>500 \mathrm{sec}$ \\
Efficiency & $>5 \%$ \\
Total impulse & \\
Total firings & \\
Tefion mass & \\
$\Delta$ & $1500 \mathrm{~N}-\mathrm{s}$ \\
$F_{\text {max }}$ & $3.75 \mathrm{millions}$ \\
Total thrust with 3 thrusters at $1 \mathrm{~Hz}(\mathrm{max})$ & $0.2 \mathrm{~kg}$ \\
Moment arm & $10 \mu \mathrm{s}$ \\
Control torque with 3 thrusters (max) & $1200 \mathrm{~N}$ \\
$d_{1}$ & $113 \mathrm{~m}$ \\
$d_{2}$ & $407 \mathrm{mN}-\mathrm{m}$ \\
Attitude deadband & $0.002 \mathrm{rad}$ \\
$K_{1}$ & $0.002 \mathrm{rad}$ \\
$K_{2}$ & $\pm 0.1 \mathrm{deg}$ \\
$K_{r}$ & 1 \\
\hline \hline
\end{tabular}

a Per a single thruster unit.

\section{Acknowledgments}

The work described in this paper was funded in whole or in part by the In-Space Propulsion Technology Program, which is managed by NASA's Science Mission Directorate in Washington, D.C., and implemented by the In-Space Propulsion Technology Office at Marshall Space Flight Center in Huntsville, Alabama. The program objective is to develop in-space propulsion technologies that can enable or benefit near and midterm NASA space science missions by significantly reducing cost, mass or travel times. The author would like io thani E. Montgomery, G. Garbe, J. Presson, A. Heaton, and M. Whorton at NASA Marshall Space Flight Center for their financial and technical support.

\section{References}

${ }^{1}$ Garbe, G. and Montgomery, E., "An Overview of NASA's Solar Sail Propulsion Project," AIAA-2003-4662, 39th AIAA/ASME/SAE/ASEE Joint Propulsion Conference and Exhibit, Huntsville, AL, July 20-23, 2003.

${ }^{2}$ Montgomery, E. and Johnson, L., "Development of Solar Sail Propulsion for Inner Solar System NASA Science Missions," AIAA-2004-3992, 40th AIAA/ASME/SAE/ASEE Joint Propulsion Conference and Exhibit, Fort Lauderdale, FL, July 11-14, 2004.

${ }^{3}$ Montgomery, E., "Technology Advancement for Solar Sail Propulsion (SSP) for NASA Science Missions to the Inner Solar System," Solar Sail Technologies and Applications Conference, NASA GSFC, Sept. 28-29, 2004. (http://lws.gsfc.nasa.gov/solar_sails_conf/Montgomery.pdf)

"Murphy, N., "Solar Polar Imager Vision Mission Overview," Solar Sail Technologies and Applications Conference, NASA GSFC, Sept. 28-29, 2004. (http://lws.gsfc.nasa.gov/solar_sails_conf/NMurphy.pdf)

${ }^{5}$ Wie, B., Thomas, S., Paluszek, M., and Murphy, D., "Propellantless AOCS Design for a 160-m, 450-kg Solar 

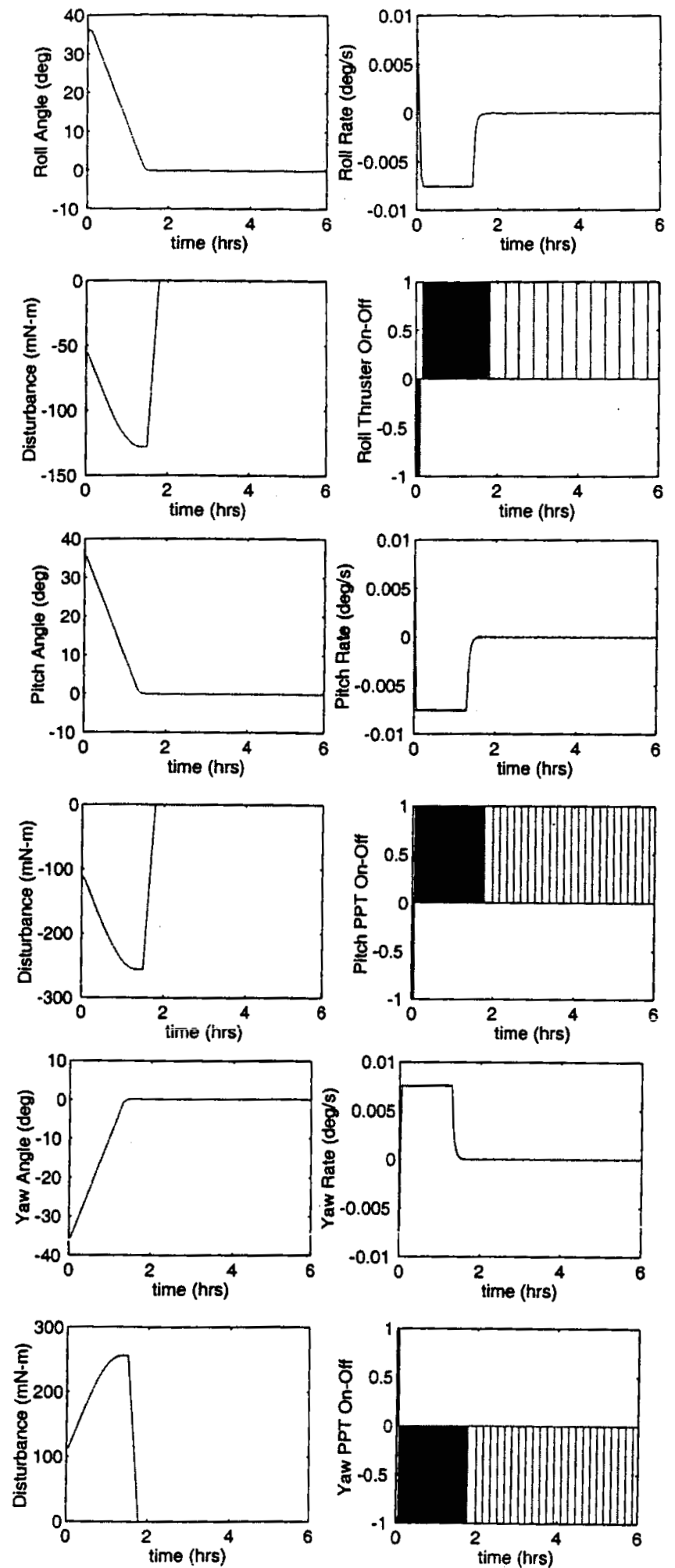

Figure 10. An attitude recovery maneuver using the microPPT-based secondary ACS in the presence of a $\mathrm{cm} / \mathrm{cp}$ offset of $0.4 \mathrm{~m}$ at $0.48 \mathrm{AU}$. After achieving steady-state, near-zero attitude errors at $t=1.5 \mathrm{hrs}$, a propellantless primary ACS (with a trim control mass speed of $5 \mathrm{~cm} / \mathrm{s}$ ) is activated to trim the sailcraft with $0.25 \%$ residual disturbances. 
Sail Spacecraft of the Solar Polar Imager Mission," AIAA 2005-3928, AIA A Joint Propulsion Conference and Exhibit, Tucson, AZ, July 10-13, 2005.

${ }^{6}$ Murphy, D. and Wie, B., "Robust Thrust Control Authority for a Scalable Sailcraft," AAS-04-285, 14th AAS/AIAA Space Flight Mechanics Conference, Maui, Hawaii, Feb. 8-12, 2004.

${ }^{7}$ Wie, B., Murphy, D., Thomas, S., and Paluszek, M., "Robust Attitude Control Systems Design for Solar Sail Spacecraft: Parts One and Two," AIAA-2004-5010 and AIAA-2004-5011, AIAA Guidance, Navigation, and Control Conference, Providence, RI, August 16-19, 2004.

${ }^{8}$ Thomas, S., Paluszek, M., Wie, B., and Murphy, D., "AOCS Performance and Stability Validation for a 160m Solar Sail with Control-Structure Interactions," AIAA-2005-3926, 41st AIAA Joint Propulsion Conference and Exhibit, Tucson, AZ, July 10-13, 2005.

${ }^{9}$ Pryor, K., Wie, B., and Mikellides, P., "Development of a Lightweight Pulsed Plasma Thruster Module for Solar Sail Attitude Control," Paper SSC04-XI-4, 18th Annual AIAA/USU Conference on Small Satellites, Logan, Utah, August 9-12, 2004.

${ }^{10}$ Salem, J. and Wie, B., "Experimental Development and Validation of a 2-kg MicroPPT Module for Solar Sail Attitude Control," under preparation.

${ }^{11}$ Brady, T., Tillier, C., Brown, R., Jimenez, A., and Kourepenis, A., "The Inertial Stellar Compass: A New Direction in Spacecraft Attitude Determination," SSC02-II-1, 16th Annual AIAA/USU Conference on Small Satellites, Logan, Utah, August 2002.

${ }^{12}$ Wie, B., "Solar Sailing Kinetic Energy Interceptor Mission for Impacting and and Deflecting Near-Earth Asteroids," AIAA-2005-3725, 41st AIAA Joint Propulsion Conference and Exhibit, Tucson, AZ, July 10-13, 2005.

${ }^{13}$ Wie, B., "Solar Sail Attitude Control and Dynamics: Parts 1 and 2," Journal of Guidance, Control, and Dynamics, Vol. 27, No. 4, pp. 526-535, 2004, pp. 536-544.

${ }^{14}$ Micci, M. and Ketsdever, A. (ed.), Micropropulsion for Small Spacecraft, Progress in Astronautics and Aerorautics, Volume 187, AIAA, Washington, DC, 2000, Chapter 3.

${ }^{15}$ Benson, S., Arrington, L., Hoskins, A., and Meckel, N., "Development of a PPT for the EO-1 Spacecraft," AIAA-99-2276, 35th AIAA Joint Propulsion Conference and Exhibit, Los Angeles, CA, June 20-24, 1999.

${ }^{16}$ Cassady, R., Hoskins, A., Campbell, M., and Rayburn, C., "A Micro Pulsed Plasma Thruster (PPT) for the Dawgstar Spacecraft," Proceedings of the 2000 IEEE Aerospace Conference, Big Sky, Montana, 2000.

${ }^{17}$ Rayburn, C., Campbell, M., and Mattick, A., "Pulsed Plasma Thruster System for Microsatellites," Journal of Spacecraft and Rockets, Vol. 42, No. 1, 2005, pp. 161-170.

${ }^{18}$ Spanjers, G., Bromaghim, D., Lake, J., Dulligan, M., White, D., Schilling J., Bushman, S., Antonsen, E., Burton, R., Keidar, M., and Boyd, I., "AFRL MicroPPT Development for Small Spacecraft Propulsion," AIAA2002-3974, 28th AIAA Joint Propulsion Conference and Exhibit, Indianapolis, IN, July 2002.

${ }^{19}$ Anthony, T., Wie, B. and Carroll, S., "Pulse-Modulated Controller Synthesis for a Flexible Spacecraft," Journal of Guidance, Control, and Dynamics, Vol. 13, No. 6, 1990, pp. 1014-1022.

${ }^{20}$ Wie, B., Space Vehicle Dynamics and Controh, AIAA Education Series, AIAA, 1998, Chapters 7 and 9. 